\title{
ACTIVITY PATTERN OF THE ORPHANED ASIATIC BLACK BEAR URSUS THIBETANUS (MAMMALIA: CARNIVORA: URSIDAE) CUBS DURING REHABILITATION PROCESSES
}

\author{
Soumya Dasgupta ${ }^{1}$, Parthankar Choudhury ${ }^{2} \&$ Parimal C. Bhattacharjee ${ }^{3}$ \\ 1,2 Department of Ecology and Environmental Science, Assam University, Silchar, Assam 788011, India \\ 1,3 Wildlife Trust of India, F-13, Sector-8, Noida, Uttar Pradesh 201301, India \\ ${ }^{1}$ soumya@wti.org.in, ${ }^{2}$ parthankar@rediffmail.com (corresponding author), ${ }^{3}$ bhattapc@wti.org.in
}

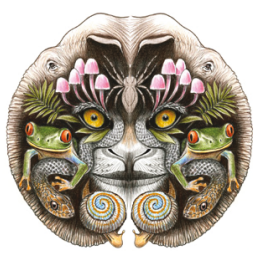

ISSN

Online 0974-7907

Print 0974-7893

OPEN ACCESS
Abstract: Five Asiatic Black Bear Ursus thibetanus cubs aged between 6.5-15 months were studied for five months using instantaneous scan sampling ( $n=3049$ scans) while they were undergoing acclimatization in the rehabilitation areas in Pakke Tiger Reserve, Arunachal Pradesh, India. During the course of the study, feeding, moving, climbing, resting and playing activities were recorded in three consecutive time periods, representing three phases of acclimatization. The frequency of climbing and moving increased considerably towards the third phase, while feeding decreased. These changes can be attributed to a learning process during acclimatization. Time spent on moving and playing differed significantly among the bears, but not climbing or feeding.

Keywords: Asiatic Black Bear, India, instantaneous group scan, Pakke Tiger Reserve, Rehabilitation.
The behaviour of bears varies considerably among species (Garshelis 2004). The range of the Asiatic Black Bear runs north-south from Russia to southern Thailand and east-west from Japan to Iran (Servheen \& Peyton 1999). Considerable work has been done on bear activity patterns throughout this distribution range, relying primarily on satellite or radio telemetry. These studies have revealed that Asiatic Black Bears are diurnal (Schaller et al. 1989; Reid et al. 1991), and observations of bears in captivity also indicate that their activities are high during dawn and dusk (Wang 1990; Hwang \& Wang
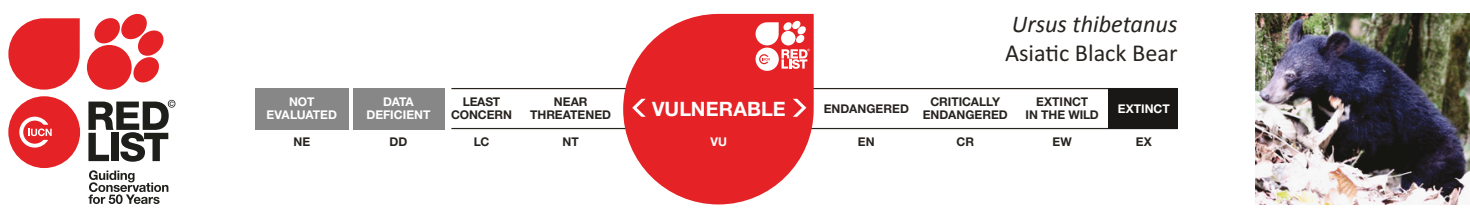

DOI: http://dx.doi.org/10.11609/JoTT.03887.6371-5

Editor: Mewa Singh, University of Mysore, Mysuru, India.

Date of publication: 26 September 2014 (online \& print)

Manuscript details: Ms \# 03887 | Received 23 December 2013 | Final received 03 September 2014 | Finally accepted 05 September 2014

Citation: Dasgupta, S., P. Choudhury \& P.C. Bhattacharjee (2014). Activity pattern of the orphaned Asiatic Black Bear Ursus thibetanus (Mammalia: Carnivora: Ursidae) cubs during rehabilitation processes. Journal of Threatened Taxa 6(10): 6371-6375; http://dx.doi.org/10.11609/JoTT.03887.6371-5

Copyright: (c) Dasgupta et al. 2014. Creative Commons Attribution 4.0 International License. JoTT allows unrestricted use of this article in any medium, reproduction and distribution by providing adequate credit to the authors and the source of publication.

Funding: Assam University, Silchar (for logistic support) and International fund for Animal Welfare (IFAW) and Wildlife trust of India (WTI) for financial support

Competing Interest: The authors declare no competing interests.

Acknowledgements: We sincerely thank Mr. Tana Tapi, Divisional Forest Officer, Pakke Tiger Reserve, and Mr. P.B. Rana, Range Officer Seijusa range, for their help and support during our work. We also express our gratitude to Mr. Aman Biri, Mr. Arun Saikia and Mr Deba Musahari for assisting in the field work. We thank Dr. N.V.K Ashraf, Mr. Sunil Kyarong, Dr. Kuladeep Roy, Mr. Tapajit Bhattacharya and Dr. Rahul Kaul of Wildlife Trust of India for their valuable suggestions. We are grateful to International fund for Animal Welfare and Mr. Vivek Menon to give us the opportunity and funding to carry out the work.
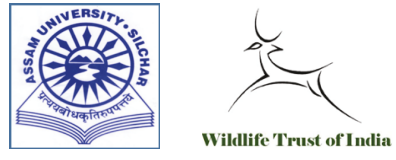


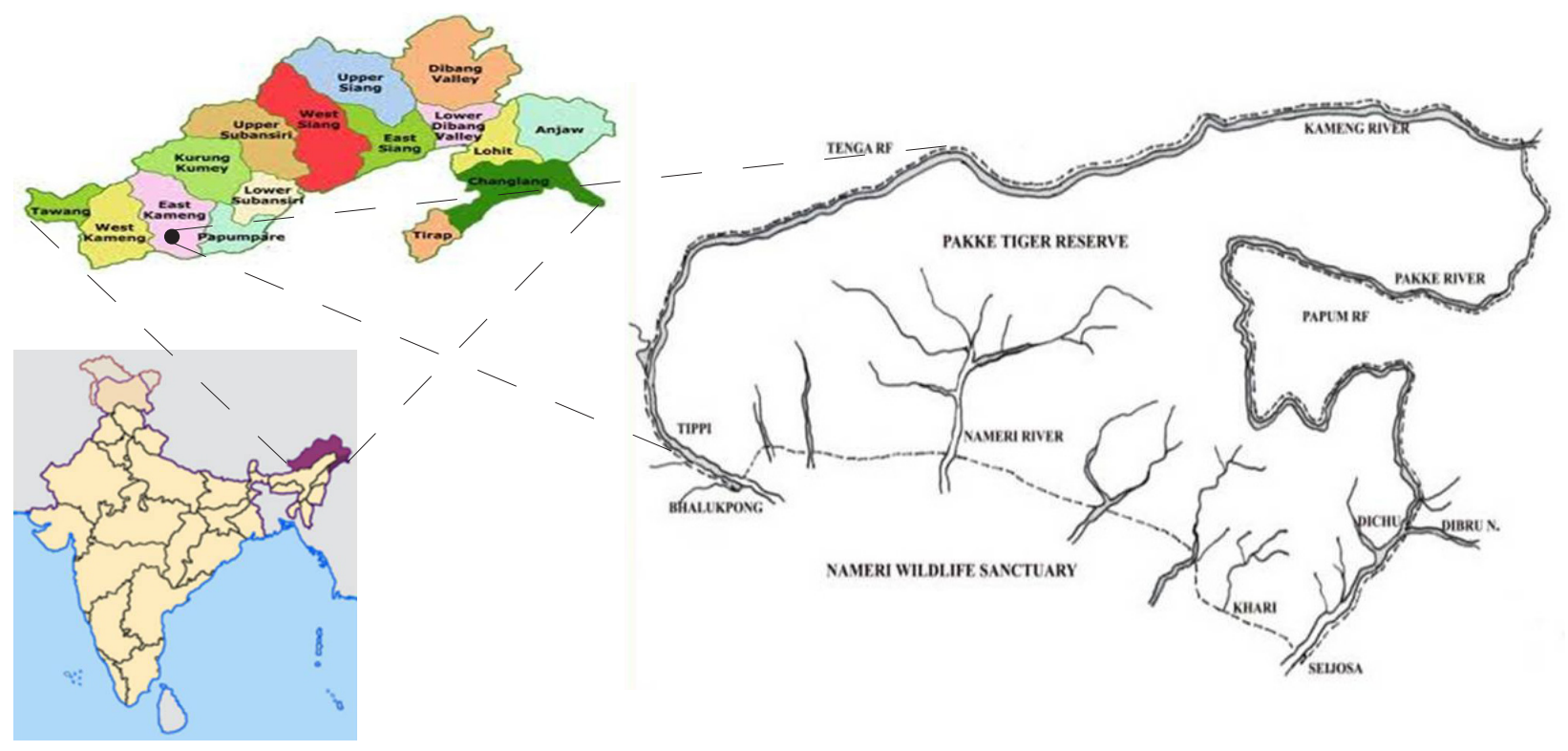

Figure 1. Location of Asiatic Black Bear cub rehabilitation site in Pakke Tiger Reserve, Arunachal Pradesh, India

1993). Most of the studies are limited to the northern distribution range of the species in Russia, Japan and parts of China (above $30^{\circ} \mathrm{N}$ latitude) (Hwang \& Garshelis 2007). In India, the foraging behaviour of the Asiatic Black Bear has been studied in Dachigam National Park (Manjrekar 1989) and Kedarnath Wildlife Sanctuary (Sathyakumar \& Viswanath 2003). Studies on radio-collared bears have also been carried out in Dachigam National Park to establish range usage and activity patterns (Charoo et al. 2011). However, until recently, there has been a lack of information on the behaviour of free-ranging bear cubs and their activity in the wild. The present study was carried out to monitor the acclimatization behaviour of five orphan Asiatic Black Bear cubs in the wild during their rehabilitation, with emphases on changes in behaviour patterns and variation among individuals.

\section{STUDY AREA}

The study was conducted near Khari, $12 \mathrm{~km}$ from Seijusa, the divisional head quarter of Pakke Tiger Reserve located at $92^{\circ} 36^{\prime}-93^{\circ} 09^{\prime} \mathrm{E} \& 26^{\circ} 54^{\prime}-27^{\circ} 16^{\prime} \mathrm{N}$ in East Kameng District of Arunachal Pradesh covering an area of $861.95 \mathrm{~km}^{2}$ (Fig. 1). The study area is hilly with several small rivulets traversing throughout. Cane, palms and bamboo thickets are common on the hill slopes. Dilenia indica and Alpinia sp. are common in the river margin forest. The area has a tropical climate with cold weather from November to February. Rainfall follows a bimodal pattern, with south-west monsoon during May to September and short rainy period from December to
April with annual mean precipitation of $2500 \mathrm{~mm}$ (Birand \& Pawar 2004). Mean ( \pm SD) maximum temperature is $29.3^{\circ} \mathrm{C} \pm 4.2$ and the mean minimum is $18.3^{\circ} \mathrm{C} \pm 4.7$ (1983 to 1995 , Tipi Orchid Research Centre).

Vegetation in the area predominantly conforms to the Assam Valley tropical semi-evergreen forest 2B/ C1 (Champion \& Seth 1968). Datta \& Rawat (2003) recorded 343 species of woody flowering plants in these forests, predominated by Euphorbiaceae and Lauraceae (Padmawathe et al. 2004). The forests are typically multi-storeyed and rich in epiphytic flora, woody lianas and climbers. The terrain is hilly, with elevations ranging from $100-1500 \mathrm{~m}$.

\section{METHODS}

We recorded the activity patterns of five Asiatic Black Bear cubs of approximately 6-15 months of age undergoing acclimatization for rehabilitation in the sub-tropical climate of the Indian eastern Himalaya. Cubs were rescued from Assam and Meghalaya (one each) and different areas of Arunachal Pradesh. These states lie within the designated distribution range of the Tibetan subspecies of the Asiatic Black Bear Ursus thibetanus thibetanus. As part of the assisted release protocol (Ashraf et al. 2008) bear cubs were kept in the in situ acclimatization enclosure in the future release area. From the time of rescue the cubs were taken care by human rehabilitators who allowed the cubs to associate with them, which is necessary for the in situ acclimatization process. Cubs were taken for daily walks 
in the forest by the rehabilitator, and in the course of such exposure to varying micro-habitats the cubs were expected to get acquainted with the availability and distribution of resources, and they were also exposed to other inter and intra-specific interactions. At the beginning of the habituation process cubs would follow the rehabilitators and supplementary food was kept inside the enclosure when the cubs were taken for their daily walk away from the enclosure. Later, when the cubs were acclimatized to the habitat they were neither dependent on the rehabilitator nor the supplementary food given inside the night shelter enclosure. Their activities were observed to document the process of acclimatization with their surroundings.

The acclimatization process was divided into three stages. In the first stage the cubs followed the rehabilitator all the times during acclimatization walks. The second stage began when the dependency of the bear cubs to the rehabilitator decreased, and they began to spend time on their own. In the third stage the cubs became completely independent of the rehabilitator, who still followed them. In all three stages supplementary food was given to the cubs only when they came back to the night shelter enclosure at the end of the daily acclimatization walk. Degree of exposure to the wild, enclosure characteristics and provisioning remained the same throughout the habituation process. The role of the rehabilitators was limited to protection and guidance during the acclimatization process so that cubs would not develop dependency. Monthwise data collected from the beginning of November 2010 to the end of March 2011 were categorised as stage 1 (from 12 November to 05 December 2010), stage 2 (from 03 January to 03 February), and stage 3 (from 26 February to 28 March). Each stage was of approximately one month duration with a gap in between to demarcate the stages. These data were analysed to document the advancement of the habituation process.

Instantaneous group scans (Altman 1974) were done at 10 minute intervals throughout the acclimatization process for all five cubs, documenting activities categorised as:

Feeding - when the animal was seen taking any food material; moving - while moving on ground; resting - when it was neither moving nor doing anything, and sitting idle; climbing - when the animal was seen climbing on a tree or moving up or down; playing - when it was playing with other animal or with some non-living objects; missing - whenever the cubs went out of sight of the observer; other activity - this includes fighting with each other, etc. as the frequencies of these activities were very low, they have been included as sundry (Images 1-4).

The data was analysed to compare activity frequencies during different stages of acclimatization. Data normality was tested using Shapiro-Wilk test. Statistical significance of the differences was also tested using the appropriate non-parametric tests. A similar analytical approach was used to test the significance of differences in time spent for different activities among the individuals.

\section{RESULTS}

A total of 3049 scan observations (SO) on the activity of five bear cubs were recorded and the data was analysed to find out occurrence of various activities. Feeding was found to be the major activity (32.04\%), followed by climbing (24.63\%), moving (20.04\%) and playing $(12.85 \%)$. Resting occurred in $2.23 \%$ of the scans and doing other activities $(0.13 \%)$ had low frequency. The cubs were missing in $8.06 \%$ of the total 3049 scan observations (Fig. 2). As the cubs grew up and became more and more accustomed in the natural environment, their activity pattern also showed some changes. Over time, missing observations increased. Simultaneously, the
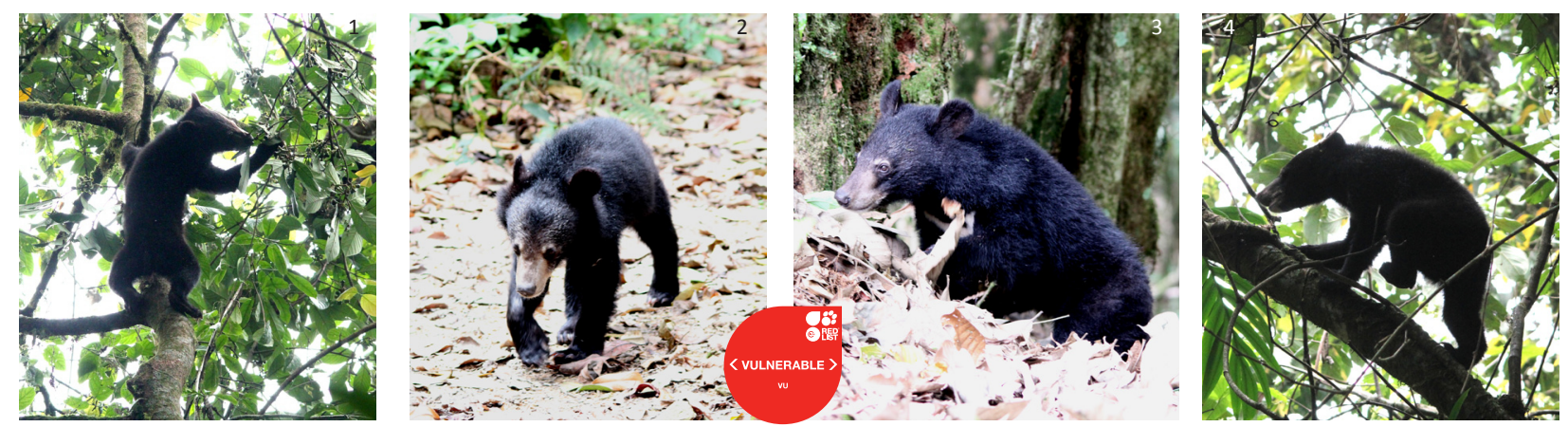

Images 1-4. Asiatic Black Bear cub during acclimatization. (C) Soumya Dasgupta

1 - feeding; 2 - moving; 3 - resting; 4 - climbing 


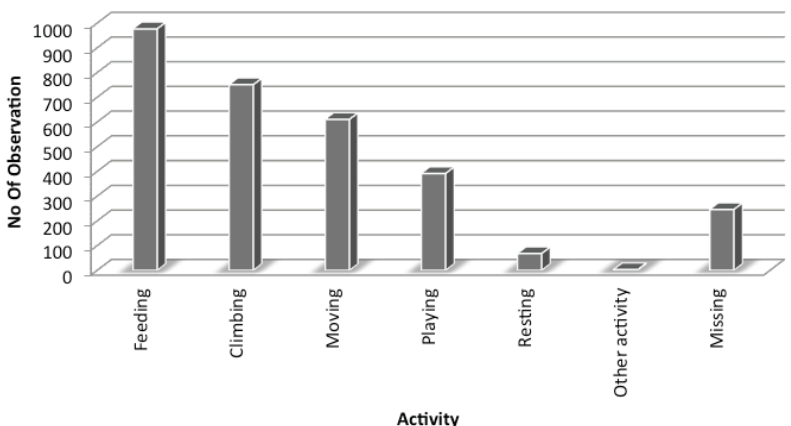

Figure 2. Various activities of the bear cubs observed in instantaneous scan

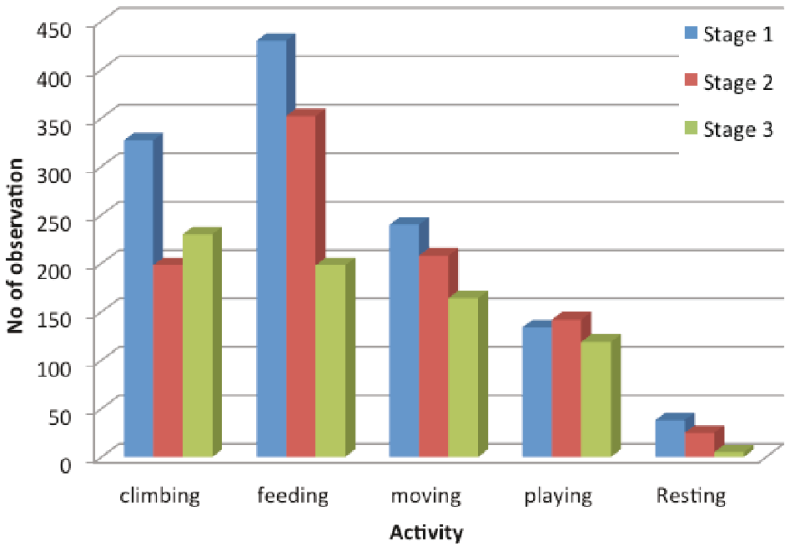

Figure 3. Percentage(s) of observed activities in instantaneous scan sampling in three successive stages of acclimatization.

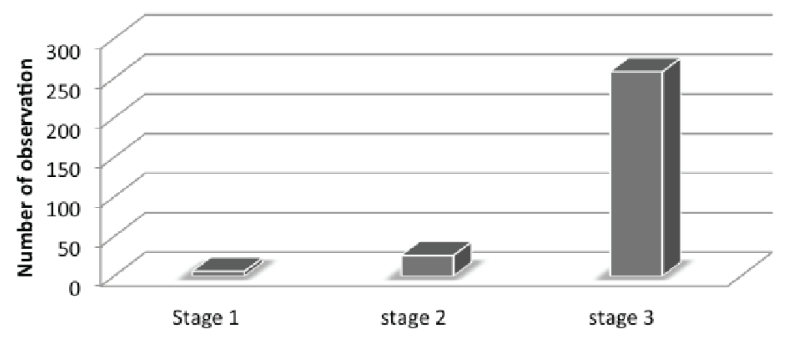

Figure 4. Missing observations during the three stages of acclimatization process.

cubs showed reduced dependency on the rehabilitators.

To ascertain whether any substantial differences existed in activity patterns among the cubs, the Kruskal Wallis test was applied. The cubs differed significantly in the amount of time they spent on moving $\left(\mathrm{H}_{0}-21.089>\right.$ $\left.\mathrm{H}_{\mathrm{c}}-9.488\right)$ and playing $\left(\mathrm{H}_{\mathrm{o}}-16.241>\mathrm{H}_{\mathrm{c}}-9.488\right)$ at $\mathrm{df}=4$, but not for climbing $\left(\mathrm{H}_{0}-1.380>\mathrm{H}_{\mathrm{c}}-9.488\right)$ and feeding $\left(\mathrm{H}_{0}-\right.$ 8.768.> $\left.\mathrm{H}_{\mathrm{c}}-9.488\right)$.

When the data was grouped into different habituation stages (from stage-1 to stage-3) of acclimatization and the same test was applied, the difference was statistically significant for all the major behavioural activities including moving $\left(\mathrm{H}_{0}-43.171>\mathrm{H}_{\mathrm{c}}-23.685\right)$, playing $\left(\mathrm{H}_{0}-\right.$ 25.449> $\left.H_{c}-23.685\right)$, climbing $\left(H_{0}-30.567>H_{c}-23.685\right)$ and feeding $\left(\mathrm{H}_{\mathrm{o}}-69.784>\mathrm{H}_{\mathrm{c}}-23.685\right)$ at $\mathrm{df}=14$.

On analysis of the scan data it was observed that the moving and playing activity increased through gradual advancement of stages. Climbing activity also increased from $1^{\text {st }}$ to $3^{\text {rd }}$ stage of acclimatizing process, although it decreased in $2^{\text {nd }}$ stage. Percentage of time spent on feeding and resting decreased as the bear cubs got acclimatized further. A significant difference in the time spent on climbing $\left(Z_{o}-2.864>Z_{c}-1.960\right.$ at $0.05 \%$ significant level), feeding $\left(Z_{0}-3.123>Z_{c}-1.960\right.$ at $0.05 \%$ significant level) and moving $\left(Z_{o}-2.599>Z_{c}-1.960\right.$ at $0.05 \%$ significant level) activities was observed, where these were found to be considerably less. But the difference was not significant in case of playing activity, although it showed a gradual decrease from first to third stage (Fig. 3). Missing observation also increased significantly through gradual advancement of stages showing the success of acclimatization process of the cubs (Fig. 4).

\section{DISCUSSION}

All the bear cubs were hand-raised in the nursery of Centre for Bear Rehabilitation and Conservation (CBRC) for about 2-4 months before they were released in the wild. When exposed to the rehabilitation site the cubs were exposed to the new ambience to which they adapted gradually at each stage of acclimatization. During the early stages of the rehabilitation process they followed the rehabilitator and other bear cubs. Heyes (1994), and Galef \& Laland (2005) reported that social learning occurs when an animal acquires a new behaviour as a result of observing or interacting with another animal. Fragaszy \& Visalberghi (1996), Lefebvre \& Giraldeau (1996), and Reader (2003) have reported that learning ability is correlated with large brain size, well-developed memory, behavioural plasticity and curiosity. Bears have all these characteristic traits to learn from the environment they are subjected to (Gittleman 1986; Gilbert 1999; Mazur \& Seher 2008). Göth \& Evans (2005) have hypothesized that even minimal parental care is worthwhile to select for social learning. This is most relevant in the context of social learning in black bears, since during post natal period, the species maintains prolonged mothercub association. During this period, cubs learn about predators, dietary choices and also foraging sites (Gilbert 1999). The same phenomenon is pertinent for bear cubs that have been rehabilitated in Arunachal Pradesh. With the rehabilitator, who acts as the foster mother the cubs 
possibly use to learn the foraging skill and utilization of optimum resources. Behavioural patterns become more specialised with the gradual advancement of the acclimatization process. In the present study it was observed that time spent on feeding activity decreased in the later stages of habituation as bears did not need to spend as much time searching for food, while time spent moving, playing and climbing increased. In the quest of better resource availability the cubs were seen to spend more time in exploring their wild environment, and with time they showed an increased tendency to climb trees, consistent with the semi-arboreal behaviour of the species often observed in wild habitats. Bear cubs usually spend a considerable period of time on the tree canopies. On one occasion a single cub was observed to make a nest using branches and leaves, and throughout the study area tree nesting by wild black bears was observed quite often.

Inter-individual differences in behavioural patterns were observed among the cubs studied. Frequencies of moving and playing differed greatly, while feeding behaviour did not differ significantly, as primarily the cubs spent time learning how to utilize available resources. Minor changes in foraging patterns were observed after the cubs became acclimatized in their own home ranges. As Asiatic Black Bear tends to live a solitary life, occasional social group formation was observed between female with cubs or male and female during breeding time (Legakul \& Mcneely 1977).

Scant information is available on the behaviour Asiatic Black Bears, many of which are killed each year in north east India as a result of man-animal conflicts. Cubs are often kept as pets, and when they become a nuisance they are either killed or handed over to the forest department. Studies of their habitat acclimatization behaviour are important for successful rehabilitation of such bears, and it is hoped that the present study will help to provide baseline information to aid this process.

\section{REFERENCES}

Altman, J. (1974). Observational study of behavior: sampling methods Behaviour 49: 227-267.

Ashraf, N.V.K., T. Dadda, P.K. Boro \& N. Akhtar (2008). Walking the Bears - Rehabilitation of Asiatic Black Bears in Arunachal Pradesh, Wildlife Trust of India, New Delhi.

Birand, A. \& S. Pawar (2004). An ornithological survey in north-east India. Forktail 20: 15-24.

Champion, H.G. \& S.K. Seth (1968). A Revised Survey of the Forest Types of India. The Manager of Publications, Government of India, New Delhi, 404pp

Charoo, S.A., L.K. Sharma \& S. Sathyakumar (2011). Asiatic Black Bearhuman interactions around Dachigam National Park, Kashmir, India. Ursus 22(2): 106-113

Datta, A. \& G.S. Rawat (2003). Foraging patterns of sympatric hornbills during the non-breeding season in Arunachal Pradesh, northeast India. Biotropica 35: 208-218.

Fragaszy, D.M. \& E. Visalberghi (1996). Social learning in monkeys: primate "primacy" reconsidered, pp. 65-84. In: Heyes, C.M. \& B.G. Galef, Jr. (eds.). Social Learning in Animals: The Roots of Culture. Academic Press. San Diego, 411pp

Galef, B.G., Jr \& K.N. Laland (2005). Social learning in animals: empirical studies and theoretical methods. Bioscience 55: 489-499.

Garshelis, D.L. (2004). Variation in Ursid life histories - is there an outlier? pp. 53-73. In Lindburg, D. \& K. Baragona (eds.). Giant Pandas: Biology and Conservation. University of California Press, Berkeley, 308pp.

Gilbert, B.K. (1999). Opportunities for social learning in bears, pp. 225235 In: Box, H.O. \& K.R. Gibson (eds.). Mammalian Social Learning: Comparative and Ecological Perspectives. Cambridge University Press, Cambridge, 424pp.

Gittleman, J.L. (1986). Carnivore brain size, behavioral ecology, and phylogeny. Journal of Mammalogy 67: 23-36.

Göth, A. \& C.S. Evans (2005). Life history and social learning: megapode chicks fail to acquire feeding preferences from conspecifics. Journal of Comparative Psychology 119: 381-386.

Heyes, C.M. (1994). Social learning in animals: categories and mechanisms. Biological Reviews 69: 207-231.

Hwang, M. \& D.L. Garshelis (2007). Activity patterns of Asiatic Black Bears (Ursus thibetanus) in the Central Mountains of Taiwan. Journal of Zoology 271: 203-209; http://dx.doi.org/10.1111/j.14697998.2006.00203.x

Hwang, M.H. \& Y. Wang (1993). A preliminary observation on a captive Asiatic Black Bear. Taipei Zoo Bulletin 5: 71-87 (Chinese, with English abstract).

Lefebvre, L. \& L. Giraldeau (1996). Is social learning an adaptive specialization? pp. 107-128. In: Heyes, C.M. \& B.G. Galef, Jr (eds.). Social Learning in Animals: The Roots of Culture. Academic Press. San Diego, 411pp.

Legakul, B. \& J.A. McNeely (1977). Mammals of Thailand. Association for the conservation of Wildlife, Bangkok, Thailand, 758pp.

Manjrekar, N. (1989). Feeding ecology of the Himalayan Black Bear (Selenarctos thibetanus Cuvier) in Dachigam National Park. Master of Science Dissertation, Saurashtra University, Rajkot, India.

Mazur, R. \& V. Seher (2008). Socially learned foraging behaviour in wild Black Bears, Ursus americanus. Animal behaviour 75: 1503-1508; http://dx.doi.org/10.1016/j.anbehav.2007.10.027

Padmawathe, R., Q. Qureshi \& G.S. Rawat (2004). Effects of selective logging on vascular epiphyte diversity in a moist lowland forest of Eastern Himalaya, India. Biological Conservation 119: 81-92.

Reader, S.M. (2003). Innovation, social learning, and relative brain size in nonhuman primates, pp. 56-93. In: Fragaszy, D.M. \& S. Perry (eds.). The Biology of Traditions. Cambridge University Press, Cambridge, 476pp.

Reid, D., M. Jiang, Q.T. Teng, Z. Qin \& J. Hu (1991). Ecology of the Asiatic Black Bear (Ursus thibetanus) in Sichuan, China. Mammalia 55: 221-237.

Sathyakumar, S. \& S. Viswanath (2003). Observations on food habits of Asiatic Black Bear in Kedarnath Wildlife Sanctuary, India: preliminary evidence on their role in seed germination and dispersal. Ursus 14(1): 99-103.

Schaller, G., Q.T. Teng, K.G. Johnson, X.M. Wang, H.M. Zhang \& J.C. Hu (1989). The feeding ecology of Giant Pandas and Asiatic Black Bears in the Tangjiahe reserve, China, pp. 212-241. In: Gittleman, J.L. (ed.). Carnivore Behavior, Ecology, and Evolution. Cornell University Press, Ithaca, New York, USA, xiv+620pp.

Servheen, H. \& B. Peyton (eds.) (1999). Bears. Status Survey and Conservation Action Plan. IUCN/SSC Bear and Polar Bear Specialist Groups, IUCN - The World Conservation Union, Gland, Switzerland and Cambridge, UK, $\mathrm{x}+309 \mathrm{pp}$.

Wang, G.B. (1990). Ecological study of Asiatic Black Bear (Selenarctos thibetanus asiaticus) - distribution, habitat and captive behavior. MSc Thesis. National Taiwan Normal University, Taipei, Taiwan (Chinese, with English summary). 